\title{
Repulsa visceral ao terror mutilado: Halloween, adequado à classificação indicativa $^{1}$
}

\section{Ivan Paganotti}

Doutor em Ciências da Comunicação pela Universidade de São Paulo (USP), realizou doutorado-sanduíche sobre regulação midiática no Centro de Estudos Comunicação e Sociedade da Universidade do Minho (Portugal), com bolsa Capes/PDSE. Professor nos cursos de pós-graduação lato sensu do Digicorp da Escola de Comunicação e Artes (ECA-USP) e da Universidade Anhembi Morumbi, é membro do Observatório de Comunicação, Liberdade de Expressão e Censura (Obcom-USP) e do Grupo de Estudos de Linguagem: Práticas Midiáticas (MidiAto/ECA-USP). E-mail: ipaganotti@usp.br
Resumo: Para adequar-se a uma faixa etária da audiência mais jovem, os distribuidores brasileiros do filme de terror Halloween - O início (2007) excluíram 26 minutos do longa-metragem - quase um quarto de sua extensão original. A partir do inusitado reposicionamento da classificação estatal na crítica aos cortes, este artigo analisa como as cenas cortadas comprometem a obra, considerando que a violência é o cerne de "slasher films" e não pode ser descartada como excesso pela autocensura. Este texto também critica o modelo de cortes promovidos por produtores privados e induzido pela classificação indicativa governamental, sugerindo um novo mecanismo para apresentar maior transparência ao processo que foi considerado como uma prática inconstitucional de censura pelo Supremo Tribunal Federal.

Palavras-chave: Cinema; Horror; Censura; Liberdade de expressão; Classificação indicativa.

\section{Visceral repulse to slashed terror: Halloween, edited to fit teen ratings}

Abstract: In order to be approved to younger audiences, the Brazilian distributors of horror film Halloween (2007) cut 26 minutes from the feature film - almost a quarter of its original length. Since even the state agency responsible for media ratings denounced this editing practice, this article evaluates how these excluded scenes compromise the movie, considering that violence is essential to slasher films and cannot just be cut off as an excess in self-censorship commercial practices. This paper also criticizes the Brazilian model that induces movie producers to cut their own films in order to follow the State film ratings. This research introduces a new mechanism to give more transparency to this processes that have already been considered as an unconstitutional practice of censorship by the Brazilian Supreme Federal Court (STF).

Keywords: Cinema; Terror; Censorship; Free speech; Movie rating.

\footnotetext{
${ }^{1}$ Versão preliminar e parcial dessa pesquisa foi apresentada previamente no XVI Encontro da Sociedade Brasileira de Estudos de Cinema (Socine) em outubro de 2012, no Senac (SP).
} 


\section{Introdução: repulsa e mutilação perversa dos fluidos vitais em gêneros viscerais}

Certos gêneros cinematográficos atraem a atenção do público - e, por vezes, a crítica de especialistas ou de agentes governamentais - por sua proposta estética explicitamente apelativa de revelação de imagens de corpos em situações extremas. Trazendo à luz as imagens de emoções ou práticas comumente consideradas como tabus, escancaram na sala escura sensações e momentos de nossos corpos que podem trazer sentimentos contraditórios de repulsa, nojo, desgosto ou atração, fascínio e excitação. O fato de atrair ou repelir os olhares não depende somente das sensibilidades dos diferentes públicos a que apelam - ou repelem -, e podem indicar a própria dicotomia da representação explícita de expressões corporais que estão abertas para uma dúbia sensação simultaneamente atraente e indesejada, reveladora dos tabus culturais que recobre com a interdição os objetos de interesse a serem recalcados, visto que, como lembra Freud (2012: 114), "o que se proíbe enfaticamente deve ser objeto de forte desejo".

Ao tentar identificar esses gêneros que causam tanto revolta como fascínio ao revelar funções corporais tabus, Williams (1991: 2, tradução nossa) parte de sua experiência cotidiana ao escolher os filmes a que gostaria de assistir com seu filho e revela como tais obras podem ser classificados como "gross" - uma vulgar e desagradável sensação corporal de nojo ou repugnância:

Quando vou ao cinema com meu filho de sete anos de idade, nós frequentemente escolhemos entre categorias de filmes que prometem ser sensacionais e podem abalar fisicamente nossos corpos. Ele chama esses filmes de "nojentos" [gross]. Meu filho e eu concordamos que a graça dos filmes "nojentos" está em sua exibição de sensações que estão no limite do aceitável².

${ }^{2}$ No original: "When my seven-year-old son and I go to the movies we often select from among categories of films that promise to be sensational, to give our bodies an actual physical jolt. He calls these movies 'gross'. My son and I agree that the fun of 'gross' movies is in their display of sensations that are on the edge of respectable".
Williams (1991) avalia que o grande interesse do público por gêneros como o melodrama, o terror e a pornografia envolve justamente a resposta que esses filmes dão à necessidade de metaforizar conflitos emocionais, medos e desejos que enfrentam barreiras culturais para sua discussão aberta ou até mesmo para sua visibilidade. Com isso, não é de surpreender que autoridades que ocupem o espaço de policiamento das práticas culturais em nome da preservação de instituições culturais ou para a proteção do público tendam a manter-se vigilantes sobre esses gêneros audiovisuais que tanto atraem quanto repelem: assim, os corpos revelados pela cena cinematográfica por vezes precisam passar pelo filtro da censura antes de encontrarem seu público nas salas de exibição.

Para se distanciar das práticas de censura nas décadas autoritárias anteriores, o Manual da Nova Classificação Indicativa do Ministério da Justiça do Brasil - que recomenda as faixas etárias de audiência apropriadas a produtos audiovisuais como filmes, programas televisivos, shows e videogames - defende a "transparência" dos procedimentos de "um dos órgãos públicos com mais informações a respeito de sua atividade-fim" (BRASIL, 2006: 8). Suas diretrizes apontam uma análise sistemática de imagens e conteúdos audiovisuais que possam incomodar ou ser considerados inadequados para certas audiências ou circunstâncias - e, com isso, a classificação indicativa segue uma avaliação pormenorizada de cenas que exibem corpos que são tomados pela violência, por substâncias entorpecentes, pelo desejo ou por questões problemáticas. A identificação dessas cenas acarreta no escalonamento dos públicos que poderiam ter acesso a essas produções, em uma escala do "livre" até "apropriado para maiores de 18 anos".

Como anunciado em seu manual, seguindo o princípio de transparência inerente a um órgão público, os processos de classificação são acessíveis ao público, mas permanecem ocultos os eventuais cortes realizados pelos produtores dos filmes ou pelos canais de televisão - que pleiteiam as classificações mais brandas possíveis para ampliar seu público potencial e, por vezes, sacrificam a integridade da obra 
e cortam cenas mais ousadas que possam trazer uma classificação mais restritiva. Com isso, a classificação indicativa só salienta que os itens avaliados sofreram "adequação" - um eufemismo para os cortes (Petley, 2007: 14) promovidos não mais pelo órgão estatal, como era prática nos períodos autoritários do passado (Mattos, 2005: 126), mas por seus próprios divulgadores de acordo com diretrizes de agências governamentais.

Ainda assim, um caso recente de cortes pela autocensura surpreendeu até os próprios classificadores do Ministério da Justiça. A PlayArte Pictures já havia tentado duas vezes, sem sucesso, rever a classificação do filme de terror Halloween - O início, de 2007 (na época inapropriado para menores de 18 anos), quando, em 2009, recebeu o deferimento: após cortar surpreendentes 26 minutos da versão original de 109 minutos - quase um quarto da extensão do filme - a classificação indicativa do filme foi reduzida para 14 anos. Cenas de sexo, assassinato, crueldade e suicídio foram omitidas em troca da ampliação de seu público potencial entre as camadas mais jovens, como descrito no processo de classificação indicativa desse filme no Ministério da Justiça:

Mesmo que a temática do filme seja adulta, considerando o psicopata sanguinário que matou, entre outros, membros da própria família, é percebido um esforço de edição para remover ou deixar implícitos muitos dos assassinatos. Mesmo com repetidos assassinatos, não se percebe a crueldade no conteúdo

${ }^{3}$ Relatório de Rafael Figueiredo Vilela (estagiário/Classificação Indicativa) e Otavio Chamorro Mendoza (Coordenador de Classificação Indicativa Substituto) sobre a classificação indicativa da versão com cortes do filme Halloween - O início, que consta no PROCESSO 08017.000902/2009-15, p. 29, da Coordenação de Classificação Indicativa (COCIND) do Departamento de Justiça, Classificação, Títulos e Qualificação (Dejus) da Secretaria Nacional de Justiça (SNJ) do Ministério da Justiça. analisado: cenas fortes/impactantes estão removidas ou interrompidas ${ }^{3}$.

A prática corriqueira dos cortes para a adequação, entretanto, atraiu atenção devido a sua extensão, e levou Davi Ulisses Brasil Simões Pires, diretor do departamento de justiça responsável pela classificação, a destacar essa excepcional deformação do filme original (ver Figura 1).
Diário Oficial da Uniāo - Seçà̃o 1

Diante dos novos elementos constantes nos autos de fls. 160 a 163 , tomo insubsistente o ato deferitónio publicado no Diário Oficial de 18/05/2009, para cancelar o Pedido de Prorrogação de Estada no País do estrangeiro, requerido pelo representante legal da empresa. Determino 0 ARQUIVAMENTO do feito. Processo $\mathrm{N}^{2}$ 08000.011726/2008-45 - Carolina Maria Ojeda Estevez Diante da solicitação de cancelamento efetuada pelo representante legal da empresa, determino o ARQUTVAMENTO do Pedido de Prorrogação de Estada no País. Processo N* 08794.004631/2008-

Diante da solicitação de cancelamento efetuada pelo representante legal da empresa, determino o ARQUTVAMENTO do Pedido de Prorrogação de Estada no País. Processo N* 08018.004256/2009. 55 - Igor Risteljic

Diante da solicitação de cancelamento efetuada pelo repreentante legal da empresa, determino o ARQUTVAMENTO do Pedido de Prorrogação de Estada no País. Processo N: 08018.002767/2009. nthony Aves

Diante da solicitação de cancelamento efetuada pelo representante legal da empresa, determino o ARQUIVAMENTO do Pedido de Pronrogação de Estada FERNANDA R. SALDANHA DE AZEVEDO DEFIRO o(s) presente(s) pedido(s) de prorrogação do prazo de estada.

Processo Ne 08102.004332/2008-92 - Rufino Cassumba Bonde, até $13 / 02 / 2010$

Processo N= 08102.004335/2008-26 - Sabina Bendinha Mendes, até $13 / 02 / 2010$

Processo N= 08212.009812/2008-01 - Felipe Carlos Alvarez Villanueva, até $23 / 02 / 2010$

Processo N²08280.000651/2009-59 - Janisia Helene Lima Mota, até 28/02/2010

Processo Ne 08280.000661/2009-94 - Temidayo Omolara Omotosho, até $06 / 03 / 2010$ 08/02/2010
$\mathrm{N}^{\circ} 139$, quinta-feira, 23 de julho de 2009 TÍTULOS E QUALIFICAÇÃO

\section{DESPACHO DO DIRETOR}

Em 22 de julho de 2009

o Diretor, no uso de suas atribuições, e tendo em vista o disposto nos artigos 21, Inciso XVI, e 220 , parágrafo $3^{\circ}$. Inciso I da Constituição Federal e artigo 74 da Lei 8.069 , de 13 de julho de 1990 com base na Portaria SNJ No 08, de 06 de julho de 2006, publicada no DOU de 07 de julho de 2006, aprovando o Manual da Nova 1.220 de 11 de Julho de 2007, publicada no DOU de 13 de julho de 2007, resolve:

Processo MJ N : 08017.000902/2009-15

Titulo do Filme: "HALLOWEEN - O INICIO" Representante: Playarte Pictures

Classificação Pretendida: Não recomendada para menores de 14 (quatorze) anos

CONSIDERANDO que o filme "HALIOWEEN - O INICIO" teve sua classificação atribuida em 8 de maio de 2009 de "não recomendado para menores de 18 (dezoito) anos", por conter suicidio,

CONSIDERANDO que, ante a solicitação do requerente através do pedido de reconsideraçâo por adequação da obra e tendo o Departamento indeferido o pedido em 9 de junho de 2009.

CONSIDERANDO que, ante a solicitação de reclassificação por adequação no último dia 14, a Playarte Pictures apresentou uma versão de 83 minutos, excluindo 26 minutos de conteúdo violento da obra, comprometendo-se em exibi-la nesta última versão apresentada, resolve:

Deferir o pedido de reclassificação por adequação do filme "HALLOWEEN - O INICIO", Processo MJ NN 08017.000902/2009 15, alterando sua classificação para: "Não recomendada para menore de 14 (quatorze) anos", por conter agressão física e assassinato. DAVI ULISSES BRASIL SIMÕES PIRES
DEPARTAMENTO DE JUSTIÇA, CLASSIFICAÇÃO, Classificação Indicativa, na Portaria MJ Na 1.100 , de 14 de julho de 2006, publicada no DOU de 20 de julho de 2006 e na Portaria N crueldade e assassinato:

Figura 1: Trecho da página 58 do Diário Oficial da União de 23 de julho de 2009. A reclassificação do filme Halloween - O início está na coluna direita (BRASIL, 2009).

A partir dessa surpreendente crítica estatal que destacou a extensão excessiva dos trechos suprimidos, este trabalho analisa o prejuízo da versão com cortes propostos pela produtora e sancionados - ainda que sob o alerta dos minutos sacrificados - pela classificação indicativa. Como a obra foi desfigurada, o direito 
${ }^{4}$ No original: "Market censorship points to practices that routinely filter or restrict the production and distribution of selected ideas, perspectives, genres or cultural forms within mainstream media of communication based upon their anticipated profits and/or support for corporate values and consumerism".

${ }^{5}$ Até a finalização desta pesquisa, em outubro de 2016, ainda não havia sido publicado o acórdão da Ação Direta de Inconstitucionalidade (ADI) 2404, que julgou inconstitucional a punição em casos de desrespeito às faixas de horário de exibição televisiva de acordo com as faixas etárias da classificação indicativa. $O$ resultado do julgamento e o processo, entretanto, podem ser acompanhados pelo site do (STF) em: <http://bit.ly/2jh7ldG>. moral do diretor do filme sobre sua criação foi igualmente talhado (Bittar, 2004: 77). Ainda mais grave foi o desrespeito ao público, que assistia a um filme sem saber que houve "adequação", nem quais foram os cortes - uma falha na transparência da classificação que ainda ecoa os "filmes que sofreram mutilações grotescas e deformantes" em nosso passado autoritário (Simões, 1999: 218). Assim, é preciso avaliar como as cenas cortadas comprometeram a obra, considerando que de forma alguma a violência pode ser vista como "gratuita" ou "excessiva" em gêneros como o terror dos "slasher films" (Williams, 1991: 9): a catarse dos corpos mutilados é justamente seu cerne estético-narrativo, e acaba comprometida com a castração da autocensura. Essa imposição de autocontrole pode ser vista como uma prática do que Jansen (2010: 13) classifica como "censura do mercado":

Censura de mercado indica práticas que rotineiramente filtram ou restringem a produção ou distribuição de ideias, perspectivas, gêneros ou formas culturais específicas dentro de meios de comunicação massivos tradicionais, baseandose em seu lucro antecipado e/ou em seu apoio de valores corporativos e no consumismo. (JANSEN, 2010: 13, tradução nossa). ${ }^{4}$

Entretanto, no caso específico em foco, a corporação privada que procurava ampliar o público potencial do filme sacrificou os próprios valores que atrairiam a audiência ao produto que ofertavam - as imagens excessivas de violência e sexualidade - para garantir uma base mais ampla entre as faixas etárias mais jovens - que seriam barradas pela classificação indicativa caso as cenas inadequadas fossem mantidas. Com as cenas originais, o filme teria ficado restrito a um público menor, o que impactaria o lucro da empresa; sem as imagens, um público maior poderia ter sido atraído, mas uma rede de fãs de produções de terror, frustrados pelo tom brando da versão que chegou às telas brasileiras, acabou por divulgar críticas que operaram como um desincentivo ao público geral no final. O sacrifício das cenas violentas pela bilheteria, dessa forma, foi frustrado pela própria audiência, irada pelos cortes revelados na comparação com versões originais disponíveis em mercados estrangeiros, como será visto a seguir.

\section{O levante burocrático da blogosfera contra cortes mercadológicos}

Além do atraso de quase dois anos entre o lançamento do filme nos EUA e sua distribuição no Brasil, o público nacional também foi tolhido pelos cortes e demonstrou sua frustração e revolta contra a distribuidora. Paradoxalmente, diversos artigos publicados em sites sobre cinema baseiam-se justamente no trecho do Diário Oficial da União que aprovava a reclassificação, com o alerta sem precedente sobre os 26 minutos cortados (BITO, 2009), e ecoam a crítica estatal em reclamações contra a produtora que promoveu os cortes (ver Figura 2).

Em primeiro lugar, surpreende o uso inusitado do veículo oficial do antigo aparato censório, tomado como aliado do público na defesa da liberdade de expressão, o que revela os limites da "transparência" sobre o processo e, consequentemente, os cortes. Esse reposicionamento da classificação indicativa é ainda mais estranho se considerarmos que a própria constitucionalidade de seus mecanismos coercitivos ${ }^{5}$ passava nesse período por revisão no Supremo Tribunal Federal (STF) (PAGANOTTI, 2012: 126-127). Durante os anos em que a produtora se preparava para exibir esse filme no Brasil, o STF avaliava se seria inconstitucional obrigar canais de televisão a exibirem conteúdo considerado pela classificação indicativa como inapropriado para determinadas faixas etárias antes dos horários reservados para esses materiais, no final da noite. Recentemente, em agosto de 2016, a maioria dos ministros dessa corte considerou, ao final, que a punição das emissoras que desrespeitassem essas faixas de horário seria realmente inconstitucional, visto que a classificação realizada pelo Ministério da Justiça só poderia ser indicativa, como seu próprio nome aponta, e não obrigatória. Alguns dos ministros inclusive apontaram, em suas considerações, que ao Estado brasileiro seria possível somente classificar os produtos audiovisuais e exigir a 
publicidade dessa classificação, sem punir com multas ou até com a suspensão da programação das emissoras que desrespeitassem as faixas etárias indicadas, o que poderia ser visto como uma prática de censura por parte dos ministros (BRASIL, 2016).

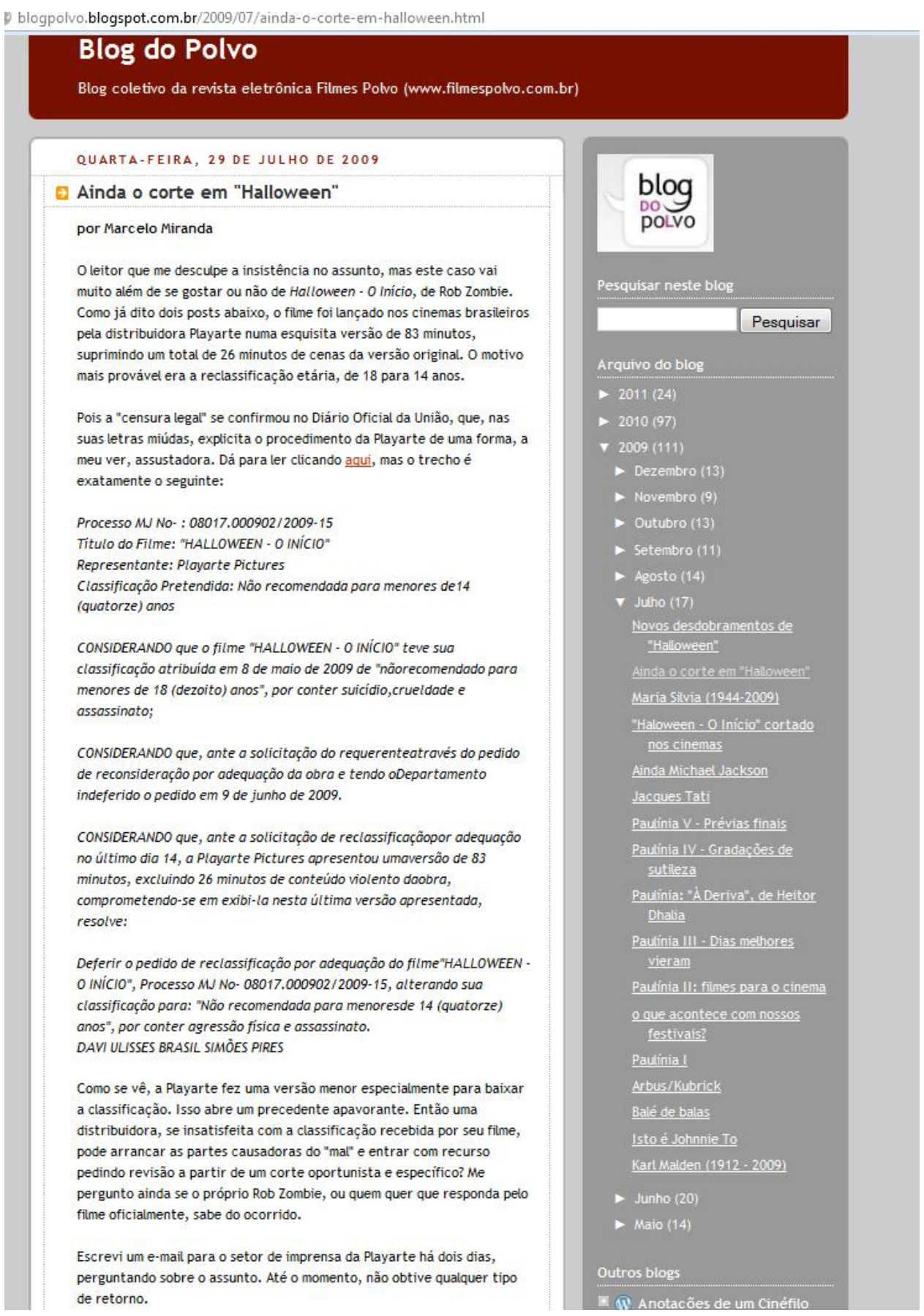

Figura 2: Blog do Polvo repercute a denúncia dos cortes em Halloween com o trecho do Diário Oficial da União (MIRANDA, 2009).

No debate acerca dos cortes do filme Halloween - O início, entretanto, o sistema estatal que induz e permite a proibição se reposiciona como denunciante dos abusos; o público, em cujo nome se classifica, torna-se uma vítima indefesa; e a culpa é concentrada nos interesses particulares da produtora, que se preocupa em ampliar seu lucro nas bilheterias (RANDALL, 1968: 215) à custa do respeito à obra cinematográfica e aos que buscavam nesse filme justamente as cenas mais drásticas do terror. Críticas como a apresentada pelo blogueiro Vítor Mendes, do site Cinema em foco, evidencia que as imagens dos corpos dilacerados são cortadas em nome do público que mais as quer, e deixa claro que o único desejo a ser satisfeito é o da produtora em obter a maior bilheteria possível: 
Excelente programa nos Estados Unidos, o lançamento de Halloween torna-se uma das maiores catástrofes do cinema de terror aqui no Brasil ao ser lançado neste mês de julho completamente cortado pela distribuidora PlayArte e ainda por cima sem nem $1 / 10$ de toda a violência [...]. O trabalho porco da distribuidora brasileira conseguiu acabar com um - na minha humilde opinão [sic] - novo clássico do terror e do suspense, adaptando-o para a ridícula classificação etária de 14 anos que visa, obviamente, abranger um maior número de espectadores no cinema, sem se importar com a notória situação ridícula em que deixa o filme perante as audiências de nosso país. [...] Os cortes conseguem ser tão ruins que fazem uma gravação impecável parecer um típico filme $B$ ao interromper as músicas de suspense do nada, mostrar situações que aparentemente teriam um desfecho e então passar para uma outra cena sem ao menos se preocupar em dar explicações quanto ao que ocorreu na passagem anterior. (MENDES, 2009).

Parte da crítica aos cortes efetuados pela produtora do filme utiliza uma estratégia que ecoa os mecanismos adotados pela própria classificação indicativa ao procurar "decupar" o filme editado nos cinemas brasileiros em relação ao original. Em um cenário em que qualquer usuário da Internet pode ter acesso a cópias da versão original do filme - ainda mais porque, devido ao atraso do lançamento no Brasil, já era possível encomendar o DVD do filme norte-americano de diversos sites antes mesmo de sua exibição das telas brasileiras - blogueiros e sites de crítica de cinema realizaram uma leitura sistemática de todas as cenas do filme original que foram deixadas de fora da versão nacional devido a seu conteúdo violento, sexual ou relacionado a outras temáticas consideradas inadequadas para a audiência mais jovem, que era alvo da produtora brasileira.

Assim, como em um processo de engenharia reversa, os cortes foram revelados e a edição aberta, destacando os trechos suprimidos do "corpo" fílmico que foi mutilado em comparação com o material original. Esse mecanismo adotado pelos críticos dos cortes mimetiza os procedimentos dos funcionários da classificação indicativa e, ao mesmo tempo, das produtoras audiovisuais nacionais, que precisam seguir o guia de leitura sistematizada proposto pelo guia do Ministério da Justiça. Para Gomes e Paganotti (2012: 296), esse manual descreve a "classificação indicativa como uma objetiva decupagem - do francês découpage, que significa o corte ou análise do filme em sequências, além do próprio processo de descrição das cenas e eventos nele retratados":

Outra forma de lidar com essas tensões pode resultar no silêncio ou repressão, com uma decupagem literal do que é considerado como inadequado, ofensivo, repulsivo ou polêmico, classificando conflitos como expressões indesejadas e ocultando tudo que pode parecer extremo demais para ser visto ou discutido. (Ibid.: 298).

Paradoxalmente ecoando a decupagem sistemática de cada cena considerada como inadequada nos processos da classificação indicativa, sites como o Cineclick evidenciam justamente as cenas que foram excluídas, construindo, em negativo, um retrato das imagens ausentes após os cortes da censura (ver Figura 3).

Como destacado na descrição abaixo da cena excluída, "toda essa cena de matança, filmada de uma maneira explícita, foi limada pela distribuidora" (Figura 3), deixando de fora o objetivo principal dos realizadores do filme e o desejo do público: a revelação dos corpos mutilados. Com isso, impõe-se entre a proposta estética do filme e o interesse do público uma preocupação em deixar de fora de cena esses corpos considerados inadequados, repulsivos, violentos, sedutores ou degradantes. Apesar do interesse mercadológico da empresa distribuidora, esse fenômeno ainda é resultado de um mecanismo que faz parte de um aparato estatal de controle que se ocupa do papel de apontar à sociedade quais imagens seriam apropriadas para quais públicos - nesse caso, quais representações do 
corpo seriam toleráveis para jovens com, pelo menos, 14 anos. Citelli (2010) destaca que essa preocupação "moralista" de tutela das audiências mais jovens em relação aos conteúdos subversivos dos meios de comunicação massivos está na gênese tanto dos estudos sobre comunicação e recepção dos públicos quanto em seu cruzamento com o campo da educação, no início do século XX:

No plano interno dos Estados Unidos, tratava-se de preservar a saúde moral dos jovens, supostamente incapazes de separar o joio do trigo, impotentes para discriminar o certo e o errado, frágeis em seu aparelho perceptual, sugestionáveis e prontos para cometer os possíveis desatinos e transgressões eventualmente expostos pela ficção televisiva, noticiários e programas de humor. Vale dizer, a questão residia em circundar as novas gerações, vigiando os mediadores de imaginários, símbolos, representações, a fim de que não provocassem desvios de conduta, comportamentos, levando as audiências juvenis a assimilarem valores não condizentes àqueles preconizados pelo one way of life. (Ibid., 2010: 71).

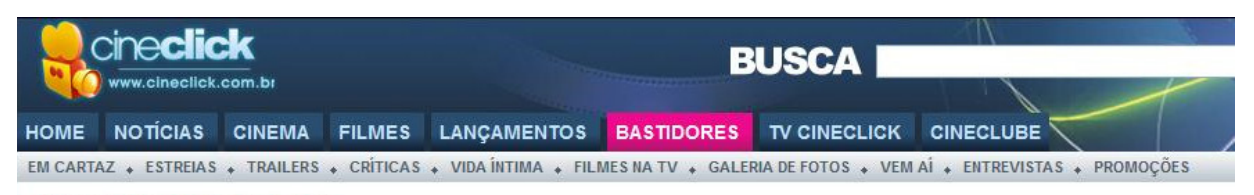

GALERIA DE FOTOS

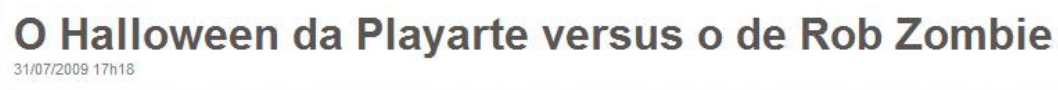
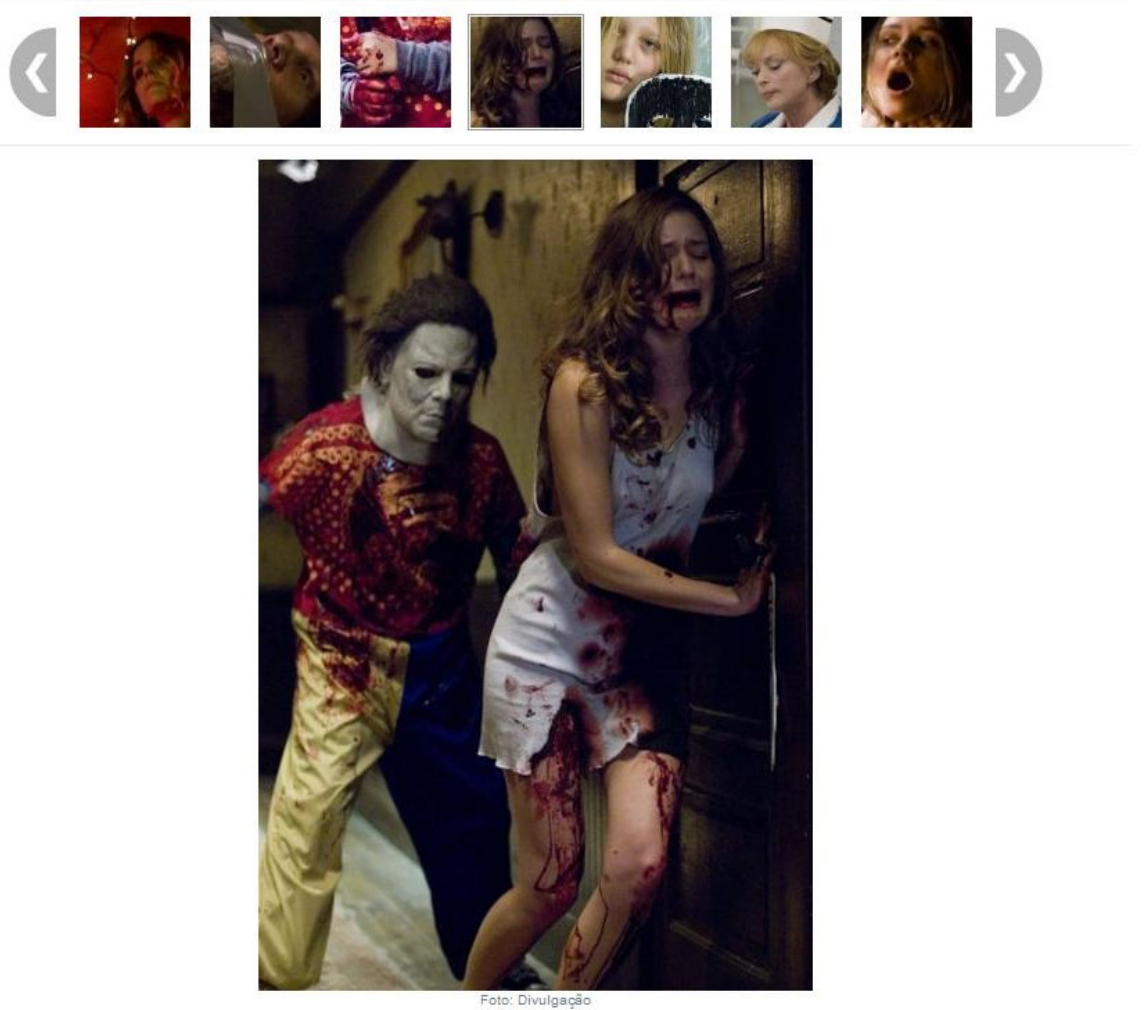

A última vítima dessa noite é Judith (Hanna Hall), irmã mais velha do protagonista. Toda essa cena de matança, filmada de uma maneira explicita, foi limada pela distribuidora. É um filme feito para pessoas de 18 anos que está sendo exibido numa versão para 14.
suicidio.

Figura 3: Página Cineclick compara e critica cortes em "Halloween" (O HALLOWEEN..., 2009).

Esse controle moral surge como resposta a uma característica identificada posteriormente por Williams (1991) em alguns gêneros cinematográficos culturalmente desprezados pela crítica - mas de grande atração para a audiência justamente por apelarem às reações emotivas e corporais e às sensações sugeridas nas grandes telas. Entre esses "gêneros corporais" [body genres] (WILLIAMS, 1991: 4), o terror soma-se ao melodrama e à pornografia por uma faceta comum que une suas propostas estéticas distintas: nos três casos encontramos emoções expressas pelo corpo dos personagens - respectivamente, o medo, o sofrimento 
e o estímulo sexual - que pretendem ser mimetizados diretamente pelo corpo das audiências, criando uma resposta que reproduza os estímulos com gritos, lágrimas e excitação sexual (loc. cit.). Dessa forma, o que a censura - estatal ou privada - procuraria fazer é "castrar" o corpo fílmico para cortar esse cordão umbilical behaviorista que amarra a sugestão subversiva dos filmes à reação das audiências impressionáveis. Apagando os sinais repulsivos da emoção que toma o controle dos corpos nas telas pela violência, temática adulta ou pelo sexo, procura-se também domar a resposta dos corpos submissos da plateia.

Entretanto, como a crítica do site Cineclick já havia destacado anteriormente (Figura 3), Halloween "é um filme feito para pessoas de 18 anos que está sendo exibido numa versão para 14 . Acho que isso dá a ideia do tipo de mutilação que foi feita". Críticas como essas e como a também já apresentada por Mendes (2009) ressaltam que os cortes no corpo fílmico "mutilaram" a narrativa e as imagens até o ponto em que não podem mais instilar interesse no público que buscava esse gênero de terror justamente para saciar sua sede por seus excessos de violência, sexo, drogas e temática adulta. A excitação instigada ante as promessas de correntes de sangue, lágrimas e sexo acaba frustrada devido ao corte desses fluidos vitais em nome da proteção de plateias adolescentes - um público que passa por transformações corporais e emocionais que são comumente metaforizadas nas películas de terror, pornografia e melodrama (WILLIAMS, 1991), mas que é justamente deixado de fora dessas sessões que tanto os atraem.

Seria possível afirmar que essas cenas são exploradas de forma abusiva e gratuita por filmes de terror como esse, mas Williams (1991: 6) destaca que essa exploração não pode ser vista como gratuita, já que é parte central de sua proposta estética-narrativa. Como parte da tradição do cinema "de exploração" [exploitation] que usava de imagens fortes e apelativas para promover filmes policiais, eróticos ou de terror em meados do século XX (CÁNEPA, 2009: 1), esses filmes de baixo orçamento apresentavam temáticas proibidas em produções mais comerciais - como "sexo, prostituição, vício, uso de drogas, nudez e outros assuntos considerados de mau gosto" (PIEDADE, 2002: 17). A franquia de Halloween é um marco no sucesso do subgênero classificado como "slasher", que apresenta entre suas principais características:

a figura de um assassino serial que persegue jovens isolados da civilização e expostos a riscos desnecessários, que pagam com a vida pelas atitudes supostamente irresponsáveis ou libertárias - estrutura típica do chamado slasher movie, subgênero juvenil do horror que é um dos mais explorados desde o final dos anos 1970. (CÁNEPA, 2010: 132-133).

Assim como na pornografia e no melodrama, Williams (1991) destaca a função do corpo feminino como veículo de vitimização/expressão das sensações que são transmitidas do filme à audiência. No caso particular do terror, a audiência adolescente pode identificar-se pelo pathos da heroína feminina inicialmente aterrorizada, infantilizada e casta, e sua posterior superação andrógena ao encarar e vencer o monstro, tomando frequentemente sua arma - um objeto fálico como uma faca, machado ou serra-elétrica - para "simbolicamente castrar" o vilão que antes a afligia (Ibid.: 6-7).

Não podemos esquecer que o assassino serial nesses filmes de terror é comumente visto como um "representante do ódio patriarcal contra a liberação feminina" e "como arauto do conservadorismo que ataca oportunamente os comportamentos desviantes da juventude" (CÁNEPA, 2010: 142) como a liberação dos costumes

${ }^{6}$ No original: "phallic power is granted so long as it is rigorously separated from phallic or any other sort of pleasure. For these pleasures spell sure death it this genre" (WILLIAMS, 1991: 8). e a expressão sexual, o consumo de bebidas, drogas e a socialização longe dos olhares vigilantes dos adultos. Como Williams (1991) destaca, as garotas "más" que não freiam seus desejos sexuais sucumbem nesses filmes, enquanto somente a heroína "boa" e casta pode sobreviver e vencer o monstro: assim, o "poder fálico é conquistado somente se é rigorosamente separado do prazer"6 (Ibid.: 8). 
Seguindo essa linha de argumentação, não deixa de ser irônico o paralelo da teoria fílmica com a censura do terror Halloween - O início. No filme, o conservadorismo da repressão sexual do monstro (um ser por definição desprezado, deformado e até simbolicamente castrado) mutila os corpos sensualizados dos jovens, mas é morto pela heroína casta que aterrorizava e que toma sua faca fálica ao ocupar novo papel andrógeno ativo (Ibid.). Da mesma forma, a censura mutilou as cenas mais ousadas dos corpos violentados ou sensuais de Halloween, mas foi colocada em xeque pela posição mais ativa do público, que criticou os cortes e tomou a arma castradora da tesoura que "adequou" o corpo fílmico à adequação à classificação indicativa, trazendo à luz o que foi castrado pela edição.

\section{Conclusão: uma proposta para deixar de infantilizar o público}

No caso avaliado, o fardo da culpa pela censura foi alocado na pressão mercadológica por ampliar o público potencial do filme entre os mais jovens, mesmo que fosse necessário sacrificar seu deleite com as cenas mais violentas do filme. Justamente, sacrificou-se o que o público mais queria para conseguir a maior audiência possível - um evidente caso de "censura de mercado" (JANSEN, 2010). Porém, não se pode ignorar o condicionamento do próprio sistema de classificação indicativa, que possibilita e induz os cortes por parte das produtoras e tende a calar ante essa violência - exceto em casos excepcionais, como esse.

Não podemos negar a grande evolução desde os tempos em que o estado detinha a tesoura (SIMÕES, 1999: 243), porém ainda falta um último passo na democratização efetiva desse processo: permitir que o público saiba que os cortes foram efetuados. Além do direito do consumidor em saber que o produto adquirido foi adulterado, é necessário evidenciar que foi justamente em seu nome que os cortes foram promovidos para que o público possa avaliar se deseja consumir essa obra mutilada - ou até se deve assumir seu papel crítico e exigir o produto pelo qual está pagando, ou mudanças nesses processos. Direitos, desejos e deveres: três máscaras para o cidadão, o consumidor e o agente político que restam ao público adotar para definir seu papel no palco das disputas entre o Estado e o mercado.

Essa proposta não seria impossível, nem mesmo historicamente inédita, como pode ser exemplificado pelo documento que lista os cortes sugeridos à Censura Federal pela produtora do filme Pixote, a lei do mais fraco (Brasil, 1981. Dir.

${ }^{7}$ Processo arquivado no site da Memória da Censura no Cinema Brasileiro 1964-1988, disponível em: <http://bit.ly/2iz2oLm>.
Hector Babenco) para sua veiculação pela TV em meados dos anos $1980^{7}$ (ver Figura 4), ou pela decupagem das cenas cortadas de Halloween e divulgada pelo site Cineclick (BITO, 2009).

Os processos de classificação indicativa atuais poderiam facilmente exigir das produtoras o envio dessa lista de cortes, disponibilizando a descrição das cenas omitidas e sua duração, para que o público possa saber o que foi omitido em seu nome - e pese o sacrifício de avaliar se esse sistema que permite os cortes vale a pena. Não se trata de simples honestidade intelectual e defesa dos direitos do consumidor (que já deveriam bastar para a defesa dessa iniciativa), pois está em questão, essencialmente, um direito de informação ao cidadão sobre o sistema estatal e as práticas comerciais adotadas para satisfazer seus direitos e desejos.

"A censura quase sempre se ergueu sobre o duplo argumento de Deus e de César", lembra Caldeira (2008: 16), mas "hoje, o novo bezerro de ouro chamase mercado". Entre o poder estatal e o interesse comercial, disputa-se pela proteção ou exploração de públicos mais jovens, sedentos por sangue nas telas de cinema. Assim, imagens são classificadas como inadequadas por abrirem à visibilidade aspectos considerados como repugnantes dos nossos corpos - como violência, ferimentos, desejo, entorpecimento, tristeza, enfermidade, morte, luto - e que são culturalmente ocultos. Ao retirar de cena essa escatologia, mutilando as produções culturais que ofereçam um vislumbre do que se passa por baixo 
dos panos que recobrem nossos corpos, procura-se manter o público longe dos excessos grotescos que os desviem das supostas virtudes corporais que devem ser protegidas. A imagem repugnante do corpo revela assim seu potencial subversivo e precisa ser controlada justamente quando as emoções parecem tomar conta dos corpos nas telas e nas plateias.

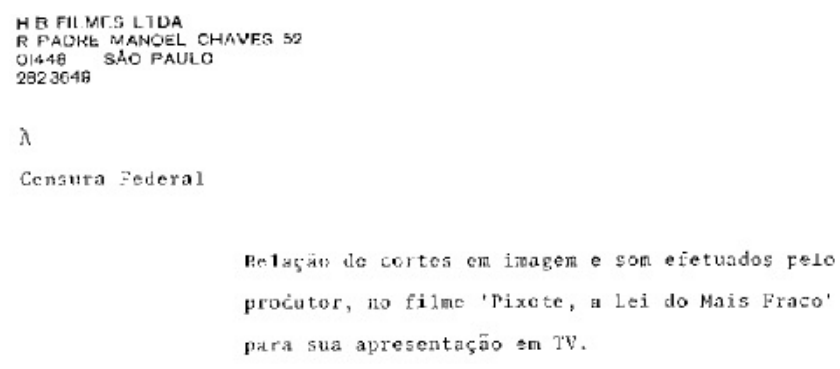

Figura 4: Descrição fornecida à censura da decupagem dos cortes efetuados pela produtora do filme Pixote, a lei do mais fraco (Brasil, 1981. Dir. Hector Babenco), em sua tentativa de exibição na TV brasileira em 1985 (RELAÇÃO DE CORTES..., [s.d.]).

Ainda assim, nem toda a plateia pode mais se sujeitar ao papel passivo de aprendizes sob a tutela governamental ou privada de seus comportamentos: não é mais possível que a proteção de crianças contra imagens ofensivas tenha o preço da infantilização do corpo e da consciência do público, alienado pelos cortes que mutilam seu entretenimento - e que o mantém distante do sistema político e comercial que comete essa violência simbólica em seu nome. Não deixa de ser revelador que pouco se questione legalmente (nem no processo recentemente concluído no STF, que considerou inconstitucional as punições atreladas aos desrespeitos à classificação indicativa televisiva) o fato de os cortes serem feitos sem qualquer transparência e informação para o público. Essa polarização entre liberdade de expressão e censura oculta outro direito importante que é desrespeitado: o direito à informação do público sobre os cortes realizados por interesses privados com anuência (ou até incentivo) do Ministério da Justiça. Afinal, trazer à tona esse sistema de cortes pode chocar muito mais do que as cenas eróticas, violentas ou lisérgicas: revela o crime obsceno contra o direito à informação e a liberdade de expressão, cometido em nome do público, mas sem seu conhecimento.

\section{Agradecimentos}

Agradeço a Davi Ulisses Brasil Simões Pires, diretor do DEJUS/SNJ, e a Alessandra Xavier Nunes Macedo, coordenadora de Classificação Indicativa do DEJUS/SNJ, por possibilitar o acesso ao processo de classificação indicativa do filme Halloween O início, enviado aos cuidados da profa. dra. Mayra Rodrigues Gomes (ECA-USP), orientadora da pesquisa de doutorado da qual se origina este estudo. 


\section{Referências}

BITO, A. Comparamos o "Halloween - O Início" dos cinemas com o de Rob Zombie. Cineclick, [s.I.], 3 ago. 2009. Disponível em: <http://bit.ly/2jnnKNh>. Acesso em: 31 jan. 2016.

BITTAR, C. A. Direito de autor. São Paulo: Forense Universitária, 2004.

BRASIL. Ministério da Justiça. Departamento de Justiça, Classificação, Títulos e Qualificação: Despacho do Diretor em 22 julho de 2009. Diário Oficial da União, Brasília, DF, 23 jul. de 2009. Seção 1, p. 58.

- Ministério da Justiça. Manual da nova classificação indicativa. Brasília, DF: Ministério da Justiça, 2006. Disponível em: <http://bit.ly/19FJrT0>. Acesso em: 31 jan. 2016.

Supremo Tribunal Federal. Inconstitucional sanção a emissora por programa fora do horário indicativo, decide STF. Notícias STF, Brasília, DF, 31 out. 2016. Disponível em: <http://bit.ly/2ct3lrt>. Acesso em: 12 out. 2016.

CALDEIRA, A. A censura a que temos direito. Media \& Jornalismo, Lisboa, v. 12, p. 9-18, 2008. Disponível em: <http://bit.ly/2iodJ46>. Acesso em: 31 jan. 2016.

CÁNEPA, L. L. Pornochanchada do avesso: o caso das mulheres monstruosas em filmes de horror da Boca do Lixo. E-compós, Brasília, DF, v. 12, n. 1, p. 1-14, jan./ abr. 2009. Disponível em: <http://bit.ly/2jl8a2j>. Acesso em: 31 jan. 2016.

. SHOCK! Slasher movie "made in Brazil". Contracampo, Niterói, n. 21, p. 131-144, ago. 2010. Disponível em: <http://bit.ly/2ikmQiV>. Acesso em: 31 jan. 2016.

CITELLI, A. Comunicação e educação: convergências educomunicativas. Comunicação, Mídia e Consumo, São Paulo, v. 7, n. 19, p. 67-85, jul. 2010. Disponível em: <http://bit.ly/2jnugUr>. Acesso em: 31 jan. 2016.

FREUD, S. Obras completas vol. 11: Totem e tabu, Contribuições à história do movimento psicanalítico e outros textos (1912-1914). São Paulo: Companhia das Letras, 2012.

GOMES, M. R.; PAGANOTTI, I. Censura além da classificação: a recepção brasileira de "A Serbian Film". Significação - Revista de Cultura Audiovisual, São Paulo, ano 39, n. 38, p. 278-301, 2012. Disponível em: <http://bit.ly/2jbn2W3>. Acesso em: 31 jan. 2016.

HALLOWEEN - O início. Direção e roteiro: Rob Zombie. Produção: Malek Akkad, Andy Gould e Rob Zombie. Intérpretes: Malcolm McDowell, Brad Dourif, Tyler Mane e Daeg Faerch. São Paulo: PlayArte, 2007. (83 min), son., color., 35 mm.

JANSEN, S. C. Ambiguities and imperatives of market censorship: the brief history of a critical concept. Westminster Papers in Communication and Culture, London, v. 7, n. 2, p. 12-30, 2010. Disponível em: <http://bit.ly/2jAjyct>. Acesso em: 31 jan. 2016.

MATTOS, S. Mídia controlada: a história da censura no Brasil e no mundo. São Paulo: Paulus, 2005.

MENDES, V. Rob Zombie's HALLOWEEN. Cinema em foco, [s.I.], 26 jul. 2009. Disponível em: <http://bit.ly/2igTerx>. Acesso em: 31 jan. 2016.

MIRANDA, M. Ainda o corte em "Halloween”. Blog do Polvo, [s.I.], 29 jul. 2009. Disponível em: <http://bit.ly/2jrT6Fc>. Acesso em: 16 jan. 2017. 
O HALLOWEEN da Playarte versus o de Rob Zombie. Cineclick, [s.l.], 31 jul. 2009.

PAGANOTTI, I. O tabu da censura: análise de uma campanha para que você "Não se engane" sobre a classificação indicativa. Rumores, São Paulo, v. 6, n. 2, p. 124-145, 2012. Disponível em: <http://bit.ly/2jbhQRT>. Acesso em: 31 jan. 2016.

PETLEY, J. Censoring the word. London: Seagull, 2007.

PIEDADE, L. de F. dos R. A cultura do lixo: horror, sexo e exploração no cinema. 2002. 222 f. Dissertação (Mestrado em Multimeios) - Universidade Estadual de Campinas, Campinas, 2002. Disponível em: <http://bit.ly/2jbfPFc $>$. Acesso em: 31 jan. 2016.

RANDALL, R. S. Censorship of the movies: the social and political control of a mass medium. Madison: University of Wisconsin, 1968.

RELAÇÃO DE CORTES em imagem e som efetuados pelo produtor, no filme 'Pixote, a Lei do Mais Fraco' para sua apresentação em TV. Memória da Censura no Cinema Brasileiro 1964-1988, [s.l.], [s.d.]. Disponível em: <http://bit.ly/2iz2oLm>. Acesso em: 16 jan. 2017.

SIMÕES, I. Roteiro da intolerância: a censura cinematográfica no Brasil. São Paulo: Senac, 1999.

WILLIAMS, L. Film bodies: gender, genre, and excess. Film Quarterly, Oakland, v. 44, n. 4, p. 2-13, 1991. 